\title{
A New Terrein Glucoside, a Novel Inhibitor of Angiogenin Secretion in Tumor Angiogenesis
}

\author{
Masayuki Arakawa, Tetsuya Someno, Manabu Kawada, Daishiro Ikeda
}

Received: April 10, 2008 / Accepted: July 7, 2008

(C) Japan Antibiotics Research Association

\begin{abstract}
Angiogenesis is a critical step for the tumor therapy. Many angiogenic factors are involved in the tumor angiogenesis. In the course of our screening for inhibitors of angiogenin secretion, one of angiogenic factors, we have isolated a new terrein glucoside (1) and terrein (2) from the fermentation broth of fungal strain Aspergillus sp. PF1381. The structure and absolute stereochemistry of $\mathbf{1}$ was determined to be $(4 S, 5 R)-5$-[( $\alpha$-D-glucopyranosyl)oxy]-4hydroxy-3-(E-1-propenyl)-2-cyclopenten-1-one on the basis of spectral and enzymatic analyses. Compounds 1 and 2 equally inhibited angiogenin secretion from androgendependent prostate cancer cells, $\mathrm{LNCaP}-\mathrm{CR}$, with $\mathrm{IC}_{50}$ values of $13 \mu \mathrm{M}$. However, both compounds did not affect VEGF secretion, another angiogenic factor. Furthermore, both compounds inhibited tube formation of human umbilical vein endothelial cells (HUVEC). These results suggested that $\mathbf{1}$ and $\mathbf{2}$ act as angiogenesis inhibitors through the inhibition of angiogenin secretion.
\end{abstract}

Keywords angiogenin, terrein glucoside, angiogenesis, angiogenic factors, prostate cancer

\section{Introduction}

Angiogenesis is considered as a key process for tumor growth, invasion and metastasis [1]. Most tumors persist for years without any angiogenic activity at the dormant

M. Kawada (Corresponding author), M. Arakawa, T. Someno, D. Ikeda: Drug Development Unit, Numazu Bio-Medical Research Institute, Microbial Chemistry Research Center, 18-24 Miyamoto, Numazu-shi, Shizuoka 410-0301, Japan, E-mail: kawadam@bikaken.or.jp stage $[2,3]$. However, tumor growth can be associated with neo-angiogenesis from pre-existing blood vessels [1]. Tumor cells synthesize and secrete several angiogenic factors and control angiogenesis via paracrine regulation of endothelial cells. Several tumor cells are known to secrete vascular endothelial growth factor (VEGF), basic-fibroblast growth factor (bFGF) and IGF-I and to stimulate tumor angiogenesis [4]. They also produce inflammatory angiogenic molecules such as COX-2, nitric oxide synthase (NOS) and IL-8 and influence neo-angiogenesis [5]. Therefore, inhibition of actions of these angiogenic factors could result in suppression of tumor growth through disruption of the tumor angiogenesis. It is reported that silibinin prevent prostate cancer by inhibiting expression and secretion of VEGF [6]. Epigallocatechin-3-gallate is also shown to suppress tumor growth through abrogation of VEGF and bFGF signaling [7].

Angiogenin was first isolated from the conditioned medium of human colon adenocarcinoma HT-29 cells [8]. The protein is a 123-amino acid polypeptide with a molecular mass of $14.1 \mathrm{kDa}$ and known to be an angiogenic factor [9]. Angiogenin expression is upregulated in a variety of tumor cells and its concentration in plasma is elevated in many types of cancer patients [10 13]. We previously established a highly tumorigenic human androgen receptor-positive prostate cancer cell, LNCaP-CR (cytokine resistance) cell line, having inflammatory cytokine resistance [14]. Furthermore, we have recently reported that LNCaP-CR cell line overexpresses angiogenin and that knockdown of angiogenin expression by transfecting angiogenin small interfering RNA into LNCaP-CR inhibits the tumor growth of LNCaP-CR cells in SCID mice [15]. These findings suggest that inhibition of angiogenin action could result in suppression of tumor growth. To identify a new anti-angiogenic agent, we 
screened for inhibitors of angiogenin secretion from LNCaP-CR cells among microbial metabolites. During our continuous screening for inhibitors of angiogenin secretion, we isolated a new terrein analog, terrein- $\alpha$-D-glucoside (1), and terrein (2) from the fermentation broth of fungal strain Aspergillus sp. PF1381. Here, we report the isolation, structure determination, and biological activity of $\mathbf{1}$.

\section{Materials and Methods}

\section{Materials}

Human cancer cell lines, PC-3 and HeLa, human umbilical vein endothelial cells (HUVEC) and human dermal fibroblast (DF) were obtained from Dainippon Pharmaceuticals (Osaka, Japan). DMEM was obtained from Nissui Seiyaku Co. (Tokyo, Japan), and MCDB-131 medium was obtained from Kurorera Kogyo Co. (Tokyo, Japan). Fetal bovine serum was obtained from ICN Biochemicals (Aurora, OH, USA). 3-(4,5-dimethylthiazol2-yl)-2,5-diphenyltetrazolium bromide (MTT) was purchased from Sigma-Aldrich (St Louis, MO, USA). Glucose C2 reagents kit (mutarotase-GOD method) was purchased from Wako Pure Chemical Industries, Ltd (Osaka, Japan).

\section{Analytical Measurement}

Melting points were obtained on a Yanagimoto micro melting point apparatus. Optical rotations were measured on a JASCO P-1030 polarimeter. UV spectra were recorded on a Hitachi 228 A spectrometer. ${ }^{1} \mathrm{H}$ - and ${ }^{13} \mathrm{C}$-NMR spectra were measured on a JEOL JNM A400 spectrometer using TMS as an internal standard. HRESI-MS spectra were measured with a JEOL JMS-T100LC spectrometer.

\section{Fermentation of Fungal Strain PF1381}

Fungal strain Aspergillus sp. PF1381 was isolated from a soil sample collected in Hachijo Island, Tokyo, Japan. A slant culture of fungal strain Aspergillus sp. PF1381 was used to inoculate 100-ml Erlenmeyer flasks. Each contained $20 \mathrm{ml}$ of a seed medium consisting of $2.0 \%$ soluble starch, $1.0 \%$ glucose, $0.2 \%$ soybean meal, $0.6 \%$ wheat germ, $0.5 \%$ polypeptone, $0.3 \%$ yeast extract, $0.2 \%$ $\mathrm{CaCO}_{3}$ in deionized water adjusted to $\mathrm{pH} 7.0$ with $\mathrm{NaOH}$ solution prior to sterilization. The flasks were incubated at $25^{\circ} \mathrm{C}$ for 72 hours on a rotary shaker at $220 \mathrm{rpm}$. Portions of $5.0 \mathrm{ml}$ of this seed culture were transferred into ten 500 $\mathrm{ml}$ Erlenmeyer flasks, each of which contained $2.5 \%$ soybean meal and water-absorbed rice $100 \mathrm{~g}$ as solid production medium. The flasks were thoroughly stirred and then statically cultured at $25^{\circ} \mathrm{C}$ for 14 days. After incubation, $1 \mathrm{~kg}$ portion of the obtained culture was extracted with 2.0 liters of $67 \%$ aq $\mathrm{Me}_{2} \mathrm{CO}$.

\section{Determination of Glucose Configuration}

The presence of D-glucose in $\mathbf{1}$ was examined by mutarotase-glucose oxidase method by Miwa and Okuda using glucose C2 reagents kit [16]. By using this kit, only D-glucose was proven to react and afford a red pigment at concentrations of $0 \sim 5 \mathrm{mM}$ in a dose-dependent manner. On the other hand, L-glucose did not react even in the concentration at $5.0 \mathrm{mM}$. Additionally, $\mathbf{1}$ and $\mathbf{2}$ in $\mathrm{H}_{2} \mathrm{O}$ as control showed no effect on this assay. Compound $\mathbf{1}$ $(0.5 \mathrm{mg})$ in $1 \mathrm{~N} \mathrm{HCl}(0.5 \mathrm{ml})$ was heated at $80^{\circ} \mathrm{C}$ for 6 hours. After the reaction mixture was neutralized with $1 \mathrm{~N}$ $\mathrm{NaOH}$, the resulting solution was applied on the assay method to afford a red pigment.

\section{Cell Culture}

LNCaP-CR $\quad\left(1 \times 10^{5} / \mathrm{ml}\right), \quad$ PC-3 $\quad\left(1 \times 10^{5} / \mathrm{ml}\right), \quad$ HeLa $\left(1 \times 10^{5} / \mathrm{ml}\right)$ and DF $\left(5 \times 10^{4} / \mathrm{ml}\right)$ were plated in a 96 -well dish (Nunc) and cultured in Dulbecco's modified Eagle's medium (DMEM) supplemented with 10\% FBS and penicillin/streptomycin. HUVEC $\left(1 \times 10^{5} / \mathrm{ml}\right)$ were cultured in MCDB-131 medium supplemented with $10 \% \mathrm{FBS}$ in a 96 well culture dish coated with gelatin. The cells were cultured for 48 hours with or without test compounds for the cytotoxicity, and the conditioned medium was applied to ELISA assay.

\section{Determination of Angiogenin and VEGF}

Angiogenin levels in culture supernatants were measured using quantitative ELISA assay. ELISA plates were coated with anti-human angiogenin monoclonal antibody $(0.5 \mathrm{mg} / \mathrm{ml}, 1: 1000, \mathrm{R} \& \mathrm{D}$ Systems, Minneapolis, MN, USA) at $4{ }^{\circ} \mathrm{C}$ over night and blocked with $0.1 \%$ BSA and $5.0 \%$ sucrose in PBS for 1 hour. The conditioned medium $(50 \mu \mathrm{l})$ was transferred to the well, and the plates were incubated at room temperature for 2 hours, and then washed with $0.05 \%$ Tween 20 in PBS four times, and incubated with $50 \mu \mathrm{l}$ of a biotinylated anti-human angiogenin antibody $(1.0 \mathrm{mg} / \mathrm{ml}, 1: 1000$, R\&D Systems, Inc., USA) per well at room temperature for 2 hours. The plates were washed four times with $0.05 \%$ Tween 20 in PBS and incubated with horseradish peroxidase avidin D $(1: 2000)$ at room temperature for 20 minutes. After washing six times with $0.05 \%$ Tween 20 in PBS, $100 \mu$ of TMB microwell peroxidase substrate (KPL, Gaithersburg MD, USA) was added into the well. After 10 minutes, stop solution $\left(50 \mu \mathrm{l}\right.$ of $\left.1.0 \mathrm{~N} \mathrm{H}_{2} \mathrm{SO}_{4}\right)$ was added into the well, the absorbance of each well was measured at $450 \mathrm{~nm}$. A standard curve was constructed to quantitate the angiogenin 
concentrations in the controls and samples. VEGF level in culture supernatants was determined using human VEGF ELISA (Pierce Endogen, Rockford, IL, USA) according to the manufacturer's protocol.

\section{Cytotoxicity Assay}

In vitro cytotoxicity was assessed with MTT assay. The cells were seeded at $1 \times 10^{4}$ or $5 \times 10^{3}$ per well in 96-well plates. The cells were cultured for 48 hours with or without test samples. Ten $\mu$ of MTT $(5.0 \mathrm{mg} / \mathrm{ml}$ in PBS) was added to each well and the plates were incubated for 4 hours. The resulting formazan products were dissolved with $20 \%$ SDS containing $10 \mathrm{mM} \mathrm{HCl}$ and the absorbance at a wavelength of $570 \mathrm{~nm}$ was measured on a micro plate reader.

\section{Analysis of Angiogenic Cytokines}

Human angiogenesis cytokines were detected by a multi human angiogenesis cytokine antibody array (RayBiotech, Norcross, GA, USA) according to the manufacturer's method.

\section{Endothelial Tube Like Formation Assay}

A co-culture system of HUVEC and DF was used to evaluate the effect of test compounds on endothelial tube formation. For detection of tube formation, we assessed immunostaining using an anti-human CD 31 antibody at day 11 after VEGF treatment (Angiogenesis Kit, Kurabo, Osaka, Japan). HUVEC and DF were cultured in the presence of $\mathbf{1 , 2}$, or suramin $(50 \mu \mathrm{M})$ as a positive control of anti-angiogenic inhibitor. The culture medium was changed to a fresh medium containing VEGF $(10 \mathrm{ng} / \mathrm{ml})$ and test compounds $(0.3,1.3,6.5,32.5 \mu \mathrm{M})$ at day 3,7 and 9 to stimulate the formation of blood-vessel-like structure. In the control groups, cells were cultured with a medium only or a medium containing VEGF through the experimental periods. At day 11, cells were fixed and immunostained with an anti-CD31/PECAM-1 antibody for endothelial cells. We analyzed the quantity of tube formation using KURABO Angiogenesis Image Analyzer (Kurabo, Osaka, Japan).

\section{Results and Discussion}

\section{Isolation Procedure for 1 and 2}

The $1 \mathrm{~kg}$ culture broth of fungal strain Aspergillus sp. PF1381 was extracted with 2.0 liters of $67 \%$ aq $\mathrm{Me}_{2} \mathrm{CO}$. The filtrate of the extracts was concentrated in vacuo to remove $\mathrm{Me}_{2} \mathrm{CO}$. The aqueous solution $(600 \mathrm{ml}, \mathrm{pH}$ 7) was applied on an HP-20 column. After washing the column with $\mathrm{H}_{2} \mathrm{O}$, active ingredients were eluted with $25 \% \mathrm{MeOH}$.
Table 1 Physico-chemical properties of terrein- $\alpha$-Dglucoside (1)

\begin{tabular}{ll}
\hline Appearance & White powder \\
Molecular formula & $\mathrm{C}_{14} \mathrm{H}_{20} \mathrm{O}_{8}$ \\
Molecular weight & 316 \\
MP & $150 \sim 153^{\circ} \mathrm{C}$ \\
HRESI-MS $(\mathrm{m} / \mathrm{z})$ & \\
$\quad$ found & $339.10760(\mathrm{M}+\mathrm{Na})^{+}$ \\
$\quad$ calcd & 339.10559 for $\mathrm{C}_{14} \mathrm{H}_{20} \mathrm{O}_{8} \mathrm{Na}$ \\
UV $\lambda_{\max } \mathrm{nm}$ in $\mathrm{H}_{2} \mathrm{O}$ & 275 \\
IR $v_{\max }(\mathrm{KBr}) \mathrm{cm}^{-1}$ & $3435,2924,1705,1635,1147,1076,1036$ \\
{$[\alpha]_{D}^{22}\left(c 0.2, \mathrm{H}_{2} \mathrm{O}\right)$} & +166.8 \\
Rf value & 0.51 \\
\hline
\end{tabular}

a Silica gel TLC (Merck Art. 1.05715), $\mathrm{CHCl}_{3}: \mathrm{MeOH}: \mathrm{H}_{2} \mathrm{O}=65: 35: 10$ (lower layer).

Fractions containing $\mathbf{1}$ and $\mathbf{2}$ were concentrated in vacuo to afford $630 \mathrm{mg}$ of dried materials. The materials (approx. $100 \mathrm{mg}$ ) were applied on a reversed-phase HPLC column (Inertsil ODS-3, 20 $\times 250 \mathrm{~mm}, 6.0 \mathrm{ml} /$ minute) and eluted with $10 \% \mathrm{CH}_{3} \mathrm{CN}$ to afford $\mathbf{1}$ and 2 . We repeated the HPLC purification 6 times to obtain $6.3 \mathrm{mg}$ of 1 and $321.6 \mathrm{mg}$ of $\mathbf{2}$, respectively.

\section{Physico-chemical Properties}

Terrein (2): a white powder; mp $123 \sim 125^{\circ} \mathrm{C}$ (lit. [17] $\mathrm{mp}$ $\left.123^{\circ} \mathrm{C}\right) ;[\alpha]_{\mathrm{D}}^{21}+160.0\left(c 0.5, \mathrm{H}_{2} \mathrm{O}\right)\left(\right.$ lit. $[17][\alpha]_{\mathrm{D}}^{22}+161.8$ (c $\left.0.6, \mathrm{H}_{2} \mathrm{O}\right)$ ); UV $\lambda_{\text {max }}$ (in $\left.\mathrm{MeOH}\right) 275 \mathrm{~nm}$; HRESI-MS $m / z$ $177.05191[\mathrm{M}+\mathrm{Na}]^{+}$(calcd for $\mathrm{C}_{8} \mathrm{H}_{10} \mathrm{O}_{3} \mathrm{Na}, 177.05276$ ); ${ }^{13} \mathrm{C}-\mathrm{NMR}\left(100 \mathrm{MHz}\right.$, acetone- $\left.d_{6}\right) \delta 19.4$ (C-8), 77.9 (C-4), 82.4 (C-5), 125.8 (C-2), 126.4 (C-6), 140.1 (C-7), 169.2 (C-3), 203.7 (C-1). Compound 1 was isolated as a white powder. The physico-chemical properties of $\mathbf{1}$ are summarized in Table 1.

\section{Structure Determination}

The molecular formula of $\mathbf{1}$ was determined to be $\mathrm{C}_{14} \mathrm{H}_{20} \mathrm{O}_{8}$ by HRESI-MS and ${ }^{13} \mathrm{C}$-NMR information (Table 2). The ${ }^{13} \mathrm{C}$-NMR spectrum $\left(\mathrm{CD}_{3} \mathrm{OD}\right)$ exhibited 14 discrete carbon signals, which were classified into one methyl, one methylene, ten methines including three $s p^{2}$ and seven $s p^{3}$ methines, one $s p^{2}$ quaternary carbon and one carbonyl carbon by the analysis of DEPT spectra. The general features of its UV and NMR spectra resembled those of $\mathbf{2}$ except for addition of five oxy-methines and one oxymethylene in the NMR spectra indicating $\mathbf{1}$ to be a glycoside of $\mathbf{2}$. The similar coupling constants and chemical shifts except for C-5 carbon due to glycosylation suggested that the relative configuration of aglycone moiety 
Table $2{ }^{13} \mathrm{C}$ - and ${ }^{1} \mathrm{H}-\mathrm{NMR}$ data of $\mathbf{1}$ in $\mathrm{CD}_{3} \mathrm{OD}$

\begin{tabular}{|c|c|c|c|}
\hline No. & $\delta_{\mathrm{C}}$ & $\delta_{\mathrm{H}}$ & $\mathrm{HMBC}$ \\
\hline 1 & 203.5 (s) & & \\
\hline 2 & $126.1(d)$ & $6.04(1 \mathrm{H}, \mathrm{s})$ & $\begin{array}{l}\text { C-1, C-4, C-5, } \\
\text { C- } 6\end{array}$ \\
\hline 3 & 171.5 (s) & & \\
\hline 4 & $76.3(d)$ & $4.93(1 \mathrm{H}, \mathrm{d}, J=2.0 \mathrm{~Hz})$ & $C-2, C-3, C-5$ \\
\hline 5 & $87.6(d)$ & $4.22(1 \mathrm{H}, \mathrm{d}, J=2.0 \mathrm{~Hz})$ & $\mathrm{C}-1, \mathrm{C}-4, \mathrm{C}-\mathbf{1}^{\prime}$ \\
\hline 6 & $126.4(d)$ & $6.45(1 \mathrm{H}, \mathrm{d}, J=16.0 \mathrm{~Hz})$ & $\mathrm{C}-2, \mathrm{C}-4, \mathrm{C}-8$ \\
\hline 7 & $142.6(d)$ & $6.85(1 \mathrm{H}, \mathrm{dq}, J=16.0,6.5 \mathrm{~Hz})$ & $\mathrm{C}-3, \mathrm{C}-8$ \\
\hline 8 & $19.5(q)$ & $1.94(3 \mathrm{H}, \mathrm{d}, J=6.5 \mathrm{~Hz})$ & $C-6, C-7$ \\
\hline $1^{\prime}$ & $101.3(d)$ & $5.22(1 \mathrm{H}, \mathrm{d}, J=3.5 \mathrm{~Hz})$ & $C-5, C-3^{\prime}$ \\
\hline $2^{\prime}$ & 73.8 (d) & $3.43(1 \mathrm{H}, \mathrm{dd}, J=9.5,3.5 \mathrm{~Hz})$ & $C-3^{\prime}$ \\
\hline $3^{\prime}$ & 74.9 (d) & $3.63(1 \mathrm{H}, \mathrm{t}, J=9.5 \mathrm{~Hz})$ & $C-4^{\prime}$ \\
\hline $4^{\prime}$ & 72.0 (d) & $3.37(1 \mathrm{H}, \mathrm{t}, J=9.5 \mathrm{~Hz})$ & $C-3^{\prime}, C-6^{\prime}$ \\
\hline $5^{\prime}$ & 74.6 (d) & $3.75(1 \mathrm{H}, \mathrm{ddd}, J=9.5,6.5,2.5 \mathrm{~Hz})$ & $C-4^{\prime}, C-6^{\prime}$ \\
\hline $6^{\prime}$ & $62.9(\mathrm{t})$ & $\begin{array}{l}3.90(1 \mathrm{H}, \mathrm{dd}, J=11.5,2.5 \mathrm{~Hz}) \\
3.65(1 \mathrm{H}, \mathrm{dd}, J=11.5,6.5 \mathrm{~Hz})\end{array}$ & $C-4^{\prime}$ \\
\hline
\end{tabular}

in $\mathbf{1}$ should be identical to $\mathbf{2}$. The sugar moiety was deduced to be a glucose based on the large vicinal coupling constants $(J=9.5 \mathrm{~Hz})$ between $2^{\prime}-\mathrm{H}$ and $3^{\prime}-\mathrm{H}$, between $3^{\prime}-\mathrm{H}$ and $4^{\prime}-\mathrm{H}$, between $4^{\prime}-\mathrm{H}$ and $5^{\prime}-\mathrm{H}$, respectively. A small coupling constant between $1^{\prime}-\mathrm{H}$ and $2^{\prime}-\mathrm{H}(J=3.5 \mathrm{~Hz})$ indicates that the glucosidic linkage to be $\alpha$. The absolute configuration of glucose moiety was examined by mutarotase-glucose oxidase method [16], in which Dglucose selectively reacts and forms a red pigment. After acid hydrolysis of $\mathbf{1}$, the reaction mixture formed a red pigment when using the assay method indicating $\mathbf{1}$ to be a D-glucoside. Additionally, positive rotation value of resulting aglycone indicated the same absolute configuration to a natural product, (+)-terrein. Thus, the absolute structure of 1 was elucidated to be $(4 S, 5 R)-5-[(\alpha-$ D-glucopyranosyl)oxy]4-hydroxy-3-(E-1-propenyl)-2cyclopenten-1-one as shown in Fig. 1.

We obtained $\mathbf{1}$ and $\mathbf{2}$ from the same broth, but $\mathbf{2}$ was not considered to be an artificial by-product of the degradation of $\mathbf{1}$, because 1 was stable under the isolation conditions
Table $\mathbf{3}$ Inhibitory activity of $\mathbf{1}$ and terrein (2) on angiogenin secretion from several human cells

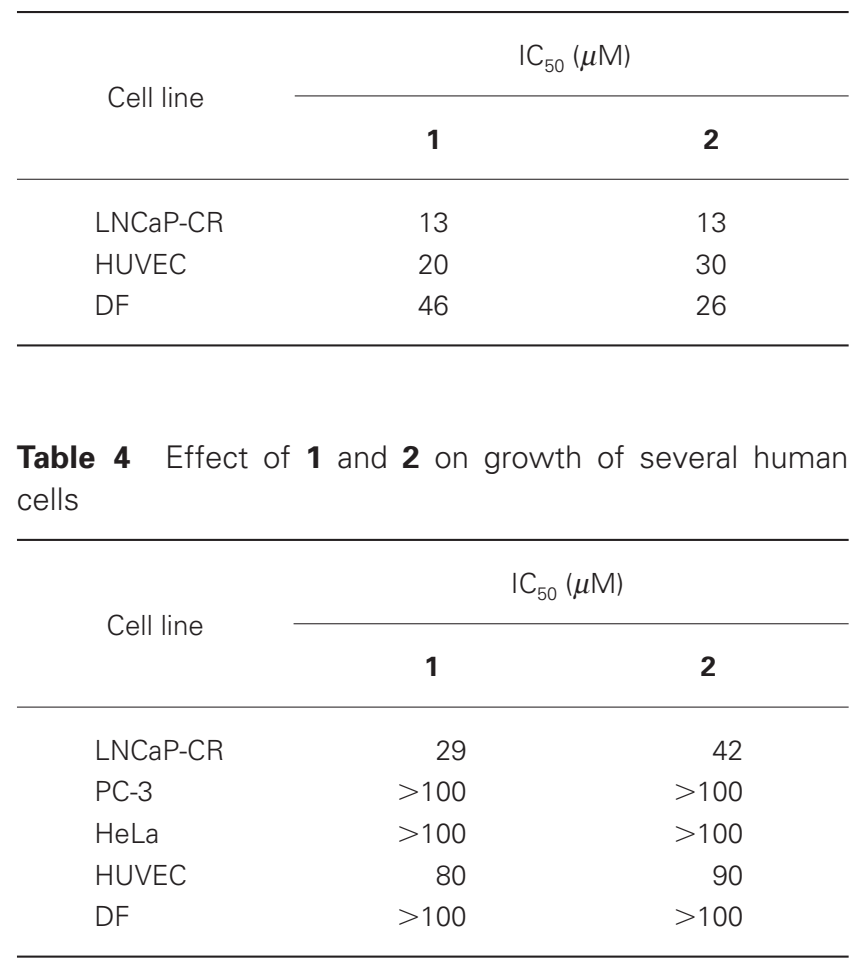

and we could obtain $\mathbf{2}$ only by severe hydrolysis of $\mathbf{1}$.

\section{Effect of 1 and 2 on Angiogenin Secretion from Prostate Cancer Cell Line, LNCaP-CR}

Terrein (2) was first isolated as a metabolite of Aspergillus terreus in 1935 [18] and was produced by other species of Aspergillus and Penicillium [19]. However, the biological effects of $\mathbf{2}$ have been almost unknown. Recently, $\mathbf{2}$ was reported to inhibit the melanogenesis [20] and the epidermal proliferation of skin equivalents [21]. Although whether $\mathbf{2}$ affects the angiogenesis-related factors has been unknown before, we have shown here that $\mathbf{1}$ and $\mathbf{2}$ inhibited angiogenin secretion from $\mathrm{LNCaP-CR}$ cells with $\mathrm{IC}_{50}$ values of $13 \mu \mathrm{M}$, respectively (Table 3 ).

To investigate whether $\mathbf{1}$ and $\mathbf{2}$ inhibit angiogenin

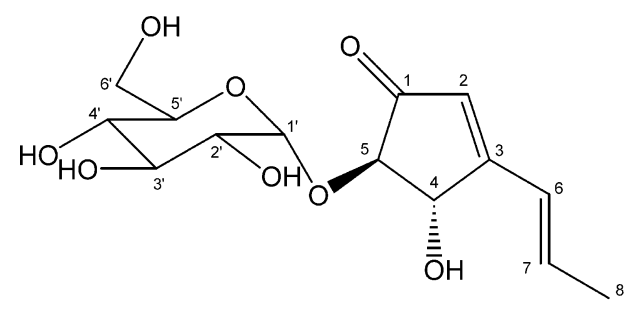

1

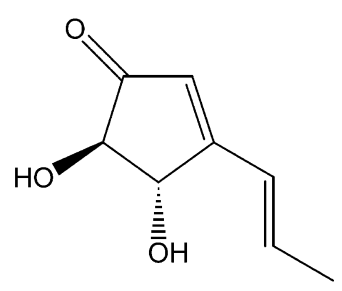

2

Fig. 1 Structures of $\mathbf{1}$ and terrein (2). 
A

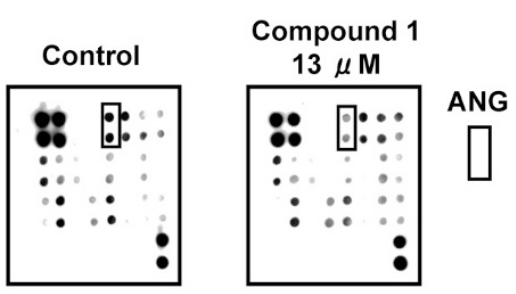

B

\begin{tabular}{|c|c|c|c|c|c|c|c|}
\hline POS & POS & NEG & NEG & ANG & EGF & ENA-78 & bFGF \\
\hline POS & POS & NEG & NEG & ANG & EGF & ENA-78 & bFGF \\
\hline GRO & IFN- $\gamma$ & IGF-1 & IL-6 & IL-8 & LEPTIN & MCP-1 & PDGF-BB \\
\hline GRO & IFN- $\gamma$ & IGF-1 & IL-6 & IL-8 & LEPTIN & MCP-1 & PDGF-BB \\
\hline PIGF & RANTES & TGF- $\beta$ 1 & TIMP-1 & TIMP-2 & TP & VEGF & IEGF-D \\
\hline PIGF & RANTES & TGF- $\beta$ 1 & TIMP-1 & TIMP-2 & TP & VEGF & EEGF-D \\
\hline & & & & & & Neg & POS \\
\hline & & & & & & Neg & POS \\
\hline
\end{tabular}

Fig. 2 Effect of 1 on secretion of angiogenesis-related cytokines from LNCaP-CR cells.

(A) Expressions of various cytokines in (B) were detected by a human angiogenesis-related cytokine array. The position of angiogenin was shown as ANG in the protein array. Neg, negative control; POS, positive control; TP, thrombopoietin; MCP-1, monocyte chemoattractant protein-1; EGF, epidermal growth factor; GRO, growth-related oncogene; TIMP, tissue inhibitor of metalloproteinase; ENA78, epithelial neutrophil-activating protein-78.

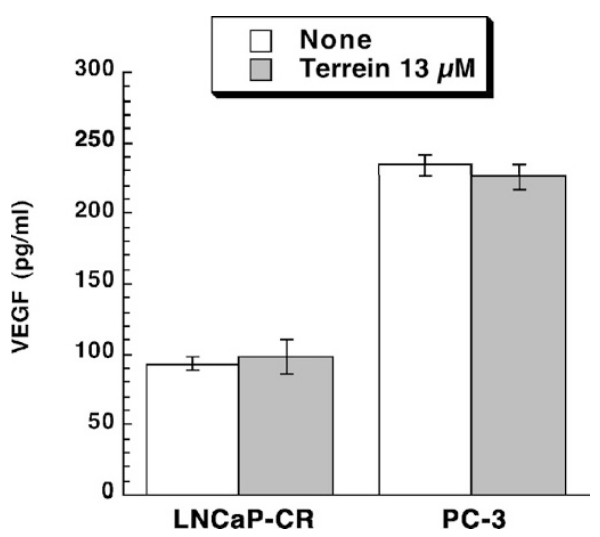

Fig. 3 Effect of $\mathbf{2}$ treatment on VEGF secretion from prostate cancer cells.

secretion specifically, we used an angiogenesis-related antibody membrane array. Our results showed that $\mathbf{1}$ specifically reduced angiogenin secretion from LNCaP-CR cells among 19 angiogenesis-related cytokines (Fig. 2). Compound $\mathbf{2}$ also specifically reduced angiogenin secretion (data not shown). Growth inhibitory activities of $\mathbf{1}$ and $\mathbf{2}$ against human tumor cell lines and human normal cell lines were assessed. As shown in Table 4, these compounds showed weak growth inhibitory activity against LNCaP-CR cells compared with other human cancer cell lines and normal cell lines. Furthermore, as shown in Figs. 2 and 3, compounds $\mathbf{1}$ and $\mathbf{2}$ did not inhibit VEGF secretion. Therefore it is not considered that $\mathbf{1}$ and $\mathbf{2}$ inhibit angiogenin secretion merely by their cytotoxic actions.

\section{Effect of 1 and 2 on Tube Formation of HUVEC}

We next investigated whether $\mathbf{1}$ and $\mathbf{2}$ could inhibit angiogenesis. It is known that angiogenin is secreted from human cancer cells and human normal cells [10]. Endogenous angiogenin in endothelial cells is related to cell proliferation and angiogenesis [22]. HUVEC cultured in serum-free medium do not divide spontaneously but can be induced to proliferate by adding angiogenin or other angiogenic factors [22]. We actually detected $156 \pm 38 \mathrm{pg} / \mathrm{ml} / 10^{5}$ cells of angiogenin by ELISA in the conditioned medium from HUVEC after 48-hour culture. As shown in Tables 3 and 4, compounds $\mathbf{1}$ and $\mathbf{2}$ inhibited angiogenin secretion from HUVEC, and showed 50\% inhibitory activity at $20 \mu \mathrm{M}$ and $30 \mu \mathrm{M}$, respectively, without significant inhibitory effect on the growth of HUVEC.

We assessed anti-tube formation activity of $\mathbf{1}$ and $\mathbf{2}$ using the in vitro angiogenesis model of HUVEC/DF co-culture system. In this model, we confirmed that the conditioned medium from HUVEC/DF co-culture system showed significant angiogenin secretion (Fig. 4C). To evaluate the effect of $\mathbf{1}$ and $\mathbf{2}$ on tube formation clearly, co-culture medium was supplemented with VEGF $(10 \mathrm{ng} / \mathrm{ml})$ for 11 days. However, VEGF did not induce the upregulation of angiogenin secretion in this co-culture system (Fig. 4C). As shown in Fig. 4A, the tube formation of HUVEC was evaluated using an ani-CD31 antibody at day 11 . Compounds 1 and $\mathbf{2}$ inhibited CD-31-positive tube formation with $\mathrm{IC}_{50}$ values of $16.5 \mu \mathrm{M}$, respectively, compared with suramin $(50 \mu \mathrm{M})$ as a positive control (Fig. 
A
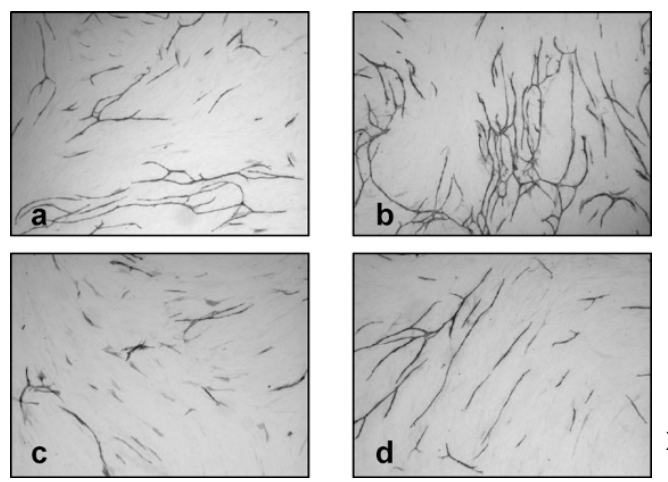
x50

B

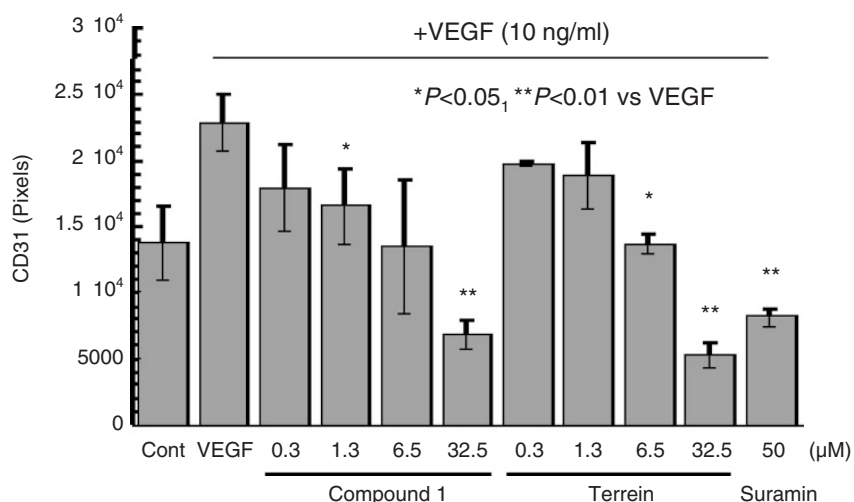

C

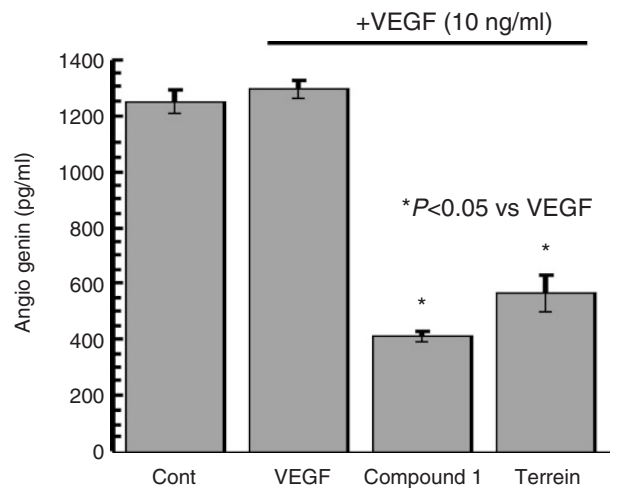

Fig. 4 Inhibition of tube formation of HUVEC by 1, 2 and suramin.

(A) Representative images of immunostaining: (a) control, (b) VEGF $10 \mathrm{ng} / \mathrm{ml}$, (c) VEGF+compound $\mathbf{1} 32.5 \mu \mathrm{M}$ and (d) VEGF+terrein (2) $32.5 \mu \mathrm{M}$. (B) An area of endothelial tubules was calculated with an Angiogenesis Image Analyzer. Five fields were examined for each experiment, and data were shown as the means of three independent experiments with SD. The inhibitory effects of the compounds were evaluated using the value in the presence of only VEGF as $100 \%$. (C) To evaluate the angiogenin secretion from HUVEC/DF conditioned medium at day 7, the amounts of angiogenin were determined by ELISA. Test compounds were used at $13 \mu \mathrm{M}$.
4A and B). Furthermore, as shown in Fig. 4C, these compounds inhibited angiogenin secretion from the HUVEC/DF co-culture at day 7. Therefore, these compounds are considered to inhibit angiogenesis of HUVEC through the inhibition of angiogenin secretion.

In conclusion, our results showed that we identified a new terrein glucoside (1) and terrein (2) as inhibitors of angiogenin secretion for anti-tumor and anti-angiogenesis therapy. These compounds also exhibited the inhibition of blood-vessel-like tube formation of HUVEC in vitro. This study suggests that inhibitors of angiogenin secretion have a potential effect of anti-angiogenesis.

Acknowledgements We are grateful to Meiji Seika Kaisha, Ltd. for fermentation of fungal strain Aspergillus sp. PF1381 and Dr. R. Sawa (Microbial Chemistry Research Center) for analysis of HRESI-MS spectra. This paper was supported in part by a grantin-aid from the Ministry of Education, Culture, Sports, Science and Technology of Japan.

\section{References}

1. Berger G, Benjamin LE. Tumorigenesis and the angiogenic switch. Nature Reviews Cancer 3: 401-410 (2003)

2. Folkman J. Role of angiogenesis in tumor growth and metastasis. Semin Oncol 29: 15-18 (2002)

3. Folkman J. Angiogenesis and angiogenesis inhibition: an overview. EXS 79: 1-8 (1997)

4. Ferrara N. VEGF and the quest for tumour angiogenesis factors. Nature Reviews Cancer 2: 795-803 (2002)

5. Chiarugi V, Magnelli L, Gallo O. Cox-2, iNOS and p53 as play-markers of tumor angiogenesis. Int $\mathrm{J}$ Mol Med 2: 715-719 (1998)

6. Singh RP, Agarwal R. Prostate cancer prevention by silibinin. Current Cancer Drug Targets 4: 1-11 (2005)

7. Rodriguez SK, Guo W, Liu L, Band MA, Paulson EK, Meydani M. Green tea catechin, epigallocatechin-3-gallate, inhibits vascular endothelial growth factor angiogenic signaling by disrupting the formation of a receptor complex. Int J Cancer 118: 1635-1644 (2006)

8. Fett JW, Strydom DJ, Lobb RR, Alderman EM, Bethune JL, Riordan JF, Vallee BL. Isolation and characterization of angiogenin, an angiogenic protein from human carcinoma cells. Biochem 24: 5480-5486 (1985)

9. Shapiro R, Riordan JF, Vallee BL. Characteristic ribonucleolytic activity of human angiogenin. Biochem 25: 3527-3532 (1986)

10. Yoshioka N, Wang Li, Kishimoto K, Tsuji T, Hu G. A therapeutic target for prostate cancer based on angiogeninstimulated angiogenesis and cancer cell proliferation. Proc Natl Acad Sci USA 103: 14519-14524 (2006)

11. Horner JJ, Greenman J, Stafford ND. Angiogenic cytokines 
in serum and plasma of patients with head and neck squamous cell carcinoma. Clin Otolaryngol Allied Sci 25: 570-576 (2000)

12. Verstovsek S, Kantarjian H, Aguayo A, Manshouri T, Freireich E, Keating M, Estey E, Albitar M. Significance of angiogenin plasma concentrations in patients with acute myeloid leukaemia and advanced myelodysplastic syndrome. Br J Haematol 114: 290-295 (2001)

13. Zhao H, Grossman HB, Delclos GL, Hwang LY, Troisi CL, Chamberlain RM, Chenoweth MA, Zhang H, Spitz MR, Wu $\mathrm{X}$. Increased plasma levels of angiogenin and the risk of bladder carcinoma: from initiation to recurrence. Cancer 104: 30-35 (2005)

14. Kawada M, Inoue H, Usami I, Takamoto K, Masuda T, Yamazaki Y, Ikeda D. Establishment of a highly tumorigenic LNCaP cell line having inflammatory cytokine resistance. Cancer Lett 242: 46-52 (2006)

15. Kawada $\mathrm{M}$, Inoue $\mathrm{H}$, Arakawa $\mathrm{M}$, Takamoto $\mathrm{K}$, Masuda $\mathrm{T}$, Ikeda D. Highly tumorigenic human androgen receptorpositive prostate cancer cells overexpress angiogenin. Cancer Sci 98: 350-356 (2007)

16. Miwa I, Okuda J, Maeda K, Okuda G. Mutarotase effect on colorimetric determination of blood glucose with -D-glucose oxidase. Clin Chim Acta 37: 538-540 (1972)
17. Kolb HC, Hoffman MR. A total synthesis of racemic and optically active terrein (trans-4,5-dihydroxy-3-[(E)-1propenyl]-2-cyclopenten-1-one). Tetrahedron: Symmetry 1: 237-250 (1990)

18. Raistrick H, Smith G. Biochemistry of microorganisms. XLII. The metabolic products of Aspergillus terreus Thom: a new mold metabolic product-terrein. Biochem J 29: 606-611 (1935)

19. Kawakubo J, Nishira H, Aoki K, Shinke R. Production of phenolic compounds by Aspergillus S-4 in sake-cake medium and identification of terrein. Biosci Biotec Biochem 57: 1208-1209 (1993)

20. Park SH, Kim DS, Kim WG, Ryoo IJ, Lee DH, Huh CH, Youn SW, Yoo ID, Park KC. Terrein: a new melanogenesis inhibitor and its mechanism. Cell Mol Life Sci 61: 2878-2885 (2004)

21. Kim DS, Cho HJ, Lee HK, Lee WH, Park ES, Youn SW, Park KC. Terrein, a fungal metabolite, inhibits the epidermal proliferation of skin equivalents. J Dermatol Sci 46: 65-68 (2007)

22. Kishimoto K, Liu S, Tsuji T, Olson KA, Hu GF. Endogenous angiogenin in endothelial cells is a general requirement for cell proliferation and angiogenesis. Oncogene 24: 445-456 (2005) 